\title{
Moving the Pendulum Back to the Middle: Reflections on and Introduction to the Inductive Research Special Issue of Journal of Business and Psychology
}

\author{
Paul E. Spector • Steven G. Rogelberg • \\ Ann Marie Ryan $\cdot$ Neal Schmitt $\cdot$ Sheldon Zedeck
}

Published online: 11 July 2014

(c) Springer Science+Business Media New York 2014

\begin{abstract}
This special issue of the Journal of Business and Psychology contains a diverse set of 13 papers that adopted an inductive approach. In addition to setting the stage for the special feature, the case for inductive research is broached. The papers in the special feature used a variety of approaches, both qualitative and quantitative, that shared the characteristic that they did not report tests of deductive theory-driven hypotheses. Rather these papers presented exploratory findings that were not limited by an explicit a priori theoretical framework. The special issue heeds calls that the field needs more inductive research to serve as the basis for theory. It is hoped that it will inspire editors of other journals to be more accepting of good inductive papers that report novel findings.
\end{abstract}

Keywords Deductive research - Deductive theory . Inductive research $\cdot$ Inductive theory $\cdot$ Special issue

Over the past 60 years, psychology has evolved from the largely atheoretical and data-driven era of behaviorism to the theory-driven hypothesis testing days of today. Organizational research has followed this trend, moving from empirical demonstration and exploratory approaches to

P. E. Spector $(\square)$

Department of Psychology, PCD 4118, University of South

Florida, Tampa, FL, USA

e-mail: pspector@usf.edu

S. G. Rogelberg

University of North Carolina Charlotte, Charlotte, NC, USA

A. M. Ryan · N. Schmitt

Michigan State University, East Lansing, MI, USA

S. Zedeck

University of California, Berkeley, Berkeley, CA, USA deductive theory-based hypothesis confirmation. Whereas the almost exclusive focus on the deductive approach has come under criticism (Hambrick 2007; Locke 2007), if anything the field's response to calls for a more balanced approach has been to double-down on the requirement for deductive theory testing in every paper. Even papers reporting meta-analyses, that just a few years in the past were largely descriptive snapshots of an area of research, now contain theoretical frameworks and hypothesis tests, often because this is what editors and reviewers demand.

There is no disputing that theories can be useful. They can help organize and synthesize what we know about a phenomenon. A good theory can help us predict and control future events. Furthermore, theories need to be tested, so for every theory we should expect to find a number of tests to confirm or disconfirm the theory's predictions. Unfortunately, in these days of over-reliance on theory generation, many if not most of our theories have been under-tested and receive few if any empirical tests beyond the original paper in which they appeared (Kacmar and Whitfield 2000).

However, there can be drawbacks when we demand that we base our science entirely on theory. By providing frameworks, theories can focus our approaches in certain directions to the exclusion of others, and discourage us from exploring new ways of thinking. If all of our studies must be based on a priori theory, there is no room in the literature for reports of new phenomena for which there are no theories, or for new ways of viewing phenomena that fail to fit any preconceived theoretical frameworks.

Another drawback to an over-emphasis on theory is that it has created a literature in which post hoc theorizing is routinely presented as tests of a priori hypotheses, leading to confirmation bias in which almost all papers report significant findings (Fanelli 2010). By requiring deductive approaches, top-tier journals create the climate in which 
Table 1 Topic areas and methodology

\begin{tabular}{lll}
\hline Topic(s) & Author/title & Keywords \\
\hline $\begin{array}{c}\text { Pre-entry/ } \\
\text { selection }\end{array}$ & Karim, M. N.,Kaminsky, S. E. Cheating, & Remote Proctoring \\
& reactions, and performance in remotely & Internet-based Testing \\
& proctored testing: an Exploratory & Unproctored Testing \\
& experimental Study & Enhanced selection
\end{tabular}

Methods

Burns, G. Christiansen, N. D., Morris, M. B., Pariard, D. A., Coaster, J. A. Effects of applicant personality on resume evaluations

Bangerter, A., Corvalan, P., Cavin, C. Storytelling in the selection interview? how applicants respond to past behavior questions

Storytelling

Mixed-methods

Communication

Narratives

Behavioral Questions

Kantrowitz, T. M., Dainis, A. How secure are unproctored pre-employment tests: analysis of inconsistent test scores

Unproctored Testing

Selection

Cognitive ability Testing

Cheating

Work-family

Inductive Research

Mixed-methods

Coping strategies work stressors and family stressors: scale development and validation

Fila, M. J., Paik, L. S., Griffeth, R.

W. Disaggregating job satisfaction: effects of perceived demands, control, and support

Job demand-Control support Theory

Job satisfaction
Data were gathered using a between- and withinsubject experimental design. Participants $(n=582)$ were asked to complete cognitive ability tests online. The researchers manipulated both proctoring/non-proctored and searchable tests/non-searchable tests. In addition to the focal variables, the researchers also directly assessed dropout rates, test performance, and participants' perceived tension and invasion of privacy

Hypotheses were tested using data gathered from two studies. In Study $1(n=266)$, participants assessed resume cues regarding their relationship with personality and hireability. In Study $2(n=122)$, human resource personnel evaluated each resume with regards to both personality and hireability. Data were analyzed using multilevel regression, while controlling for participants' rating multiple cues

Both qualitative and quantitative data were gathered. First, data from real job interviews $(n=62)$ were qualitatively assessed for the prevalence of five types of applicant responses to past behavior interview questions. Second, these data were coded based on the narrative content of stories. Finally, the researchers assessed both the relationship between applicant characteristics and response type and the relationship between response type and hiring recommendations

Data were gathered from job candidates ( $n=4,026)$ who were asked to complete an adaptive cognitive ability test under both unproctored and proctored conditions. Participants completed an unproctored screening test first, followed by a proctored confirmation test. Paired samples $t$ tests were used to identify cheating behaviors in the unproctored versus proctored tests

Both qualitative and quantitative data were gathered. First, interviews $(n=50)$ were content analyzed in order to generate a comprehensive list of coping strategies. Second, data from three different samples $(n=402)$ were used to establish the content validity of the work stressor and family stressor coping strategy scale. Finally, the researchers gathered convergent, discriminant, and criterion-related validity evidence from two additional samples $(n=300)$

Facets

Inductive
Survey data were gathered from employees of a public human services organization $(\mathrm{n}=343)$. The authors used a series of $t$ tests for dependent correlations between each demand, control, and support variable. These analyses were used to evaluate differences in effect size between each job satisfaction facet and stressors/resources 
Table 1 continued

\begin{tabular}{|c|c|c|c|}
\hline Topic(s) & Author/title & Keywords & Methods \\
\hline & $\begin{array}{l}\text { Williams, M., Emich, K. J. The } \\
\text { experience of failed humor: preliminary } \\
\text { implications for interpersonal affect } \\
\text { regulation }\end{array}$ & $\begin{array}{l}\text { Inductive } \\
\text { Humor } \\
\text { Persistence } \\
\text { Affect regulation }\end{array}$ & $\begin{array}{l}\text { Two waves of data were collected from } \\
\text { undergraduate students }(n=127) \text {. During } \\
\text { Phase 1, participants completed individual } \\
\text { difference and demographic items. During } \\
\text { Phase 2, the same participants were randomly } \\
\text { assigned to one of two conditions: the failed } \\
\text { humor narrative condition or the successful } \\
\text { humor narrative condition. Following the } \\
\text { narrative conditions, participants answered } \\
\text { questions regarding their state affect, self- } \\
\text { esteem, and humor self-efficacy }\end{array}$ \\
\hline \multirow[t]{4}{*}{$\begin{array}{l}\text { Performance/ } \\
\text { counterproductive } \\
\text { behaviors/turnover }\end{array}$} & $\begin{array}{l}\text { Becker, T. E., Marique, G. Observer } \\
\text { Effects without demand characteristics: } \\
\text { an inductive Investigation of video } \\
\text { monitoring and performance }\end{array}$ & $\begin{array}{l}\text { Video monitoring } \\
\text { Performance } \\
\text { Inductive research } \\
\text { Grounded theory }\end{array}$ & $\begin{array}{l}\text { Data were gathered using an experimental } \\
\text { design. Two experiments were conducted. In } \\
\text { Experiment } 1(n=75) \text {, an inductive approach } \\
\text { was taken. In Experiment } 2(n=139) \text {, a } \\
\text { partially inductive approach was taken. Across } \\
\text { both experiments, the researchers manipulated } \\
\text { participant's awareness of being video } \\
\text { recorded, while they completed a motor task }\end{array}$ \\
\hline & $\begin{array}{l}\text { Spector, P., Zhou, Z. E. The Moderating } \\
\text { role of gender in relationships of } \\
\text { stressors and personality with } \\
\text { counterproductive work behavior }\end{array}$ & $\begin{array}{l}\text { Counterproductive Work } \\
\text { behaviors } \\
\text { Gender } \\
\text { Job stressors } \\
\text { Relational Aggression }\end{array}$ & $\begin{array}{l}\text { Survey data were gathered from participants } \\
(n=915) \text { recruited from university classes. } \\
\text { Participants responded to questions regarding } \\
\text { their job stressors, personality characteristics, } \\
\text { and counterproductive work behavior. } \\
\text { Moderated regression analyses were used to } \\
\text { assess the interaction of gender, personality, } \\
\text { and stressors on both counterproductive work } \\
\text { behaviors and relational aggression }\end{array}$ \\
\hline & $\begin{array}{l}\text { Woo, S. E., Allen, D. G. Toward an } \\
\text { inductive theory of stayers and seekers } \\
\text { in the organization }\end{array}$ & $\begin{array}{l}\text { Turnover Intentions } \\
\text { Job search } \\
\text { Individual Differences } \\
\text { Latent class Analysis }\end{array}$ & $\begin{array}{l}\text { Data were gathered using an online survey. } \\
\text { Participants }(n=408) \text { were asked to respond } \\
\text { to questions regarding their employment } \\
\text { history, personality characteristics, current } \\
\text { work experiences, and turnover-related } \\
\text { cognition and behavior. Multinominal logistic } \\
\text { regression analyses were used to assess the } \\
\text { probability of attitudinal and dispositional } \\
\text { characteristics predicting participants' } \\
\text { membership in different latent class clusters }\end{array}$ \\
\hline & $\begin{array}{l}\text { Markham,S. E., Markhalm, I. S., } \\
\text { Braekkan, K. F. A Visual illustration of } \\
\text { induction in multilevel methods: the } \\
\text { problem of leaders awarding } \\
\text { countervailing merit components }\end{array}$ & $\begin{array}{l}\text { Within-and-Between } \\
\text { analysis (WABA) } \\
\text { Merit raise } \\
\text { Temporary bonus } \\
\text { Permanent raise }\end{array}$ & $\begin{array}{l}\text { Multilevel data were gathered from managers } \\
\text { and professionals }(n=71) \text { embedded within } \\
\text { supervisory units }(n=21) \text { at a large } \\
\text { manufacturing plant. In addition, merit pay and } \\
\text { salary data were gathered from organizational } \\
\text { records. Within-and-between analysis was used } \\
\text { to examine the relationship between raises and } \\
\text { bonuses at the individual and group level }\end{array}$ \\
\hline $\begin{array}{l}\text { Harassment/safety } \\
\text { climate }\end{array}$ & $\begin{array}{l}\text { Bergman, M. E., Payne, S. C., Taylor, A. } \\
\text { B., Beus, J. M. The shelf life of a safety } \\
\text { climate assessment: how long until the } \\
\text { relationship with safety-critical } \\
\text { incidents expires? }\end{array}$ & $\begin{array}{l}\text { Safety climate } \\
\text { Leading and Lagging } \\
\text { Aggregation } \\
\text { Indictors Measurement }\end{array}$ & $\begin{array}{l}\text { Mutlisource data were gathered from employees } \\
(n=7,467) \text { working for a large chemical } \\
\text { manufacturing company and from incident } \\
\text { records }(n=14,000) \text {. Employee survey data } \\
\text { were linked to incident records, which were } \\
\text { selected from } 2 \text { years prior and } 2 \text { years } \\
\text { following the survey period. OLS regression } \\
\text { was used to examine safety climate as a leading } \\
\text { and lagging indicator of safety }\end{array}$ \\
\hline
\end{tabular}


Table 1 continued

\begin{tabular}{|c|c|c|c|}
\hline Topic(s) & Author/title & Keywords & Methods \\
\hline & $\begin{array}{l}\text { Kath, L. M., Bulger, C. A., Holzworth, R. } \\
\text { J., Galleta, J. A. Judgments of sexual } \\
\text { harassment court case summaries }\end{array}$ & $\begin{array}{l}\text { Sexual harassment } \\
\text { Judgment analysis } \\
\text { Policy capturing } \\
\text { Brunswikian Approach }\end{array}$ & $\begin{array}{l}\text { Data were gathered from jury-eligible adults } \\
(n=55) \text {. Over the course of several days, } \\
\text { participants were asked to make judgments } \\
\text { regarding } 50 \text { one-page case summaries. Raters } \\
\text { coded potential factors included in the case } \\
\text { summaries that could influence judgments. } \\
\text { Judgment analyses were conducted to examine } \\
\text { the relationship between potential factors, or } \\
\text { "cues", and participant judgments of sexual } \\
\text { harassment }\end{array}$ \\
\hline
\end{tabular}

authors are encouraged, and in many cases editors and reviewers explicitly ask for, post hoc theorizing. This occurs even though post hoc theorizing is a practice deemed unethical by the Journal Editor Ethics code (Author 2014).

Although the Journal of Business and Psychology welcomes inductive research at any time (e.g., Ho 2012), this special feature provides a home for papers that were not driven by theory and allows authors to present their research as exploratory. The special issue heeds Locke's (2007) call for an inductive approach that allows publication of papers that do not deductively test theoretically derived hypotheses. The introductions of these papers summarized what is known about their topics and then addressed research questions. The purpose was to provide new insights into phenomena and to show us how constructs are related. The papers here provide insights into organizational phenomena unconstrained by hypothesis tests that largely must be confirming. The insights these papers provide will hopefully provide raw material for future theories.

One of the surprising things we learned in serving as editors for this special issue is that the deductive approach is so firmly entrenched in our collective consciousness that many authors struggled without the framework of theory. Some of the papers submitted failed to capture the spirit of the inductive approach at all. In some cases, authors just submitted the usual deductive papers, perhaps because they were rejected by other journals for not having strong enough theory. These papers had hypotheses based on some theoretical framework and were not a good fit for the special issue. In other cases, papers had introductions that contained theory and arguments leading to some hypothesized relationships, but the hypotheses were just unstated. Perhaps these papers had been submitted elsewhere, and the authors just deleted the hypotheses without refocusing the introduction in a more inductive way. The ideal paper was positioned as addressing an important research question. Although background on the topic was provided, the background did not lead to the expectation that results should come out in a particular way. Rather it led to uncertainty about what to expect in the results.
The special issue contains 13 inductive papers that cover a variety of topics, and the authors applied various methods including qualitative. In Table 1, we list all of the papers grouping them into topic area. We also note the methodology used.

This special issue had two goals. The first was to provide a home for good inductive papers that would contribute to our literature in significant ways. This answers Locke's (2007) call for inductive papers that can provide the raw material for future theories. The second was to demonstrate the value of the inductive approach, to be a proof of concept. We hope that this special issue will motivate editors at other journals to change their policies and welcome high quality inductive papers. The past 60 years has seen the pendulum swing from induction and emphasis on empiricism to deduction and the almost total rejection of exploratory approaches today. It is time to let the pendulum swing back to the middle where both deduction and induction are equally valued. Hopefully, this special issue will be a small step in that direction.

\section{References}

Author. (2014). Journal Editor Ethics 2.0. Retrieved April 23, 2014, from http://editorethics.uncc.edu/code.aspx.

Fanelli, D. (2010). "Positive" results increase down the hierarchy of the sciences. PLOS ONE, 5(4), 1-10.

Hambrick, D. C. (2007). The field of management's devotion to theory: too much of a good thing? Academy of Management Journal, 50(6), 1346-1352. doi:10.5465/AMJ.2007.28166119.

Ho, V. T. (2012). Interpersonal counterproductive work behaviors: distinguishing between person-focused versus task-focused behaviors and their antecedents. Journal of Business and Psychology, 27(4), 467-482.

Kacmar, K. M., \& Whitfield, J. M. (2000). An additional rating method for journal articles in the field of management. Organizational Research Methods, 3(4), 392-406. doi:10.1177/ 109442810034005.

Locke, E. A. (2007). The case for inductive theory building. Journal of Management, 33(6), 867-890. doi:10.1177/01492063073 07636. 